\title{
Survey of plasma proteins in children with progeria pre-therapy and on-therapy with lonafarnib
}

\author{
Leslie B. Gordon ${ }^{1}$, Susan E. Campbell ${ }^{2}$, Joseph M. Massaro ${ }^{3}$, Ralph B. D’Agostino Sr. ${ }^{3}$, Monica E. Kleinman ${ }^{4}$, Mark W. Kieran ${ }^{5}$ \\ and Marsha A. Moses ${ }^{6}$
}

BACKGROUND: Hutchinson-Gilford progeria syndrome (HGPS) is an ultra-rare, fatal, segmental premature aging syndrome caused by the aberrant lamin A protein, progerin. The protein farnesyltransferase inhibitor, lonafarnib, ameliorates some aspects of cardiovascular and bone disease.

METHODS: We performed a prospective longitudinal survey of plasma proteins in 24 children with HGPS (an estimated $10 \%$ of the world's population at the time) at baseline and on lonafarnib therapy, compared with age- and gendermatched controls using a multi-analyte, microsphere-based immunofluorescent assay.

RESULTS: The mean levels for 23/66 (34.8\%) proteins were significantly lower and 7/66 (10.6\%) were significantly higher in HGPS samples compared with those in controls $(P \leq 0.05)$. Six proteins whose concentrations were initially lower normalized with lonafarnib therapy: interleukins 1a, 7, and 13, beta-2 microglobulin, C-reactive protein, and myoglobin. Alpha-2 macroglobulin, a protease inhibitor associated with stroke, was elevated at baseline and subsequently normalized with lonafarnib therapy.

CONCLUSION: This is the first study to employ a multianalyte array platform in HGPS. Novel potential biomarkers identified in this study should be further validated by correlations with clinical disease status, especially proteins associated with cardiovascular disease and those that normalized with lonafarnib therapy.

$\mathbf{H}$ utchinson-Gilford Progeria Syndrome (HGPS) is, in most cases, a sporadic, autosomal dominant, "premature aging" disease in which children die primarily of heart attacks at an average age of 14.6 years (range 1-26 years) (1). Incidence is estimated at 1 in 8 million live births (2), and prevalence is 1 in 20 million living individuals (3). Children experience normal fetal and early postnatal development. Between several months and 1 year of age, abnormalities in growth and body composition become readily apparent (4).
Severe failure to thrive ensues, heralding generalized lipoatrophy, with apparent wasting of limbs, circumoral cyanosis, and prominent veins (5). Children reach a final height of $\sim 1 \mathrm{~m}$ and weight of $\sim 14 \mathrm{~kg}$. Bone dysplasia includes clavicular resorption, coxa valga, distal phalangeal resorption, facial disproportion (a prominent, slim nose and receding mandible), and short stature. Dentition is severely delayed (6). Tooth eruption may be delayed for many months, and primary teeth may persist for the duration of life. Secondary teeth are present, but may or may not erupt. Skin looks thin with sclerodermatous areas and almost complete hair loss (7). Some skin findings are variable in severity and include areas of discoloration, stippled pigmentation, tightened areas that can restrict movement, and areas of the dorsal trunk where small $(1-2 \mathrm{~cm})$ soft bulging skin is present. Joint contractures, due to ligamentous and skin tightening, limit range of motion. Intellectual development is normal in HGPS. Transient ischemic attacks and strokes may ensue as early as 4 years of age, but more often they occur in the later years (8). Death results primarily from sequelae of widespread atherosclerosis. In a comprehensive retrospective study, causes of death in HGPS were cardiovascular failure $(80 \%)$, head injury or trauma (10\%), stroke (4\%), respiratory infection superimposed on cardiovascular disease (4\%), and complications from anesthesia during surgery (2\%) (1).

We previously conducted a prospective single-arm clinical trial of lonafarnib for children with HGPS (NCT00425607) (9). Lonafarnib was well tolerated. The primary outcome measure (improved rate of weight gain) was achieved; cardiovascular distensibility, as assessed via carotid-femoral pulse wave velocity and carotid artery echodensity, was improved; radial bone structural rigidity and sensorineural hearing increased. There was preliminary evidence of decreased headache, transient ischemic attack, and stroke rates (10). To date, both the primary and secondary outcomes have been evaluated after 2 years of therapy.

The aim of this study was to initiate the development of shorter-term clinically meaningful biomarkers, so that

\footnotetext{
${ }^{1}$ Department of Pediatrics, Hasbro Children's Hospital and Warren Alpert Medical School of Brown University, Providence, Rhode Island; ${ }^{2}$ Center for Gerontology and Health Care Research, Brown University, Providence, Rhode Island; ${ }^{3}$ Department of Mathematics and Statistics, Boston University, Harvard Clinical Research Institute, Boston, Massachusetts; ${ }^{4}$ Divisions of Critical Care, Boston Children's Hospital and Harvard Medical School, Boston, Massachusetts; ${ }^{5}$ Pediatric Neuro-Oncology, Dana-Farber Boston Children's Cancer and Blood Disorders Center, Boston, Massachusetts; ${ }^{6}$ The Vascular Biology Program and The Department of Surgery, Boston Children's Hospital and Harvard Medical School, Boston, Massachusetts. Correspondence: Leslie B. Gordon (Leslie_Gordon@brown.edu) 


\section{Abnormal plasma proteins in progeria $\quad$ Articles}

evaluation of disease status and improvement with treatment can be assessed earlier than the current clinical outcomes. In recent years, large-scale multiplex assays have been developed and have succeeded in expanding the capacity to explore potential disease biomarkers for a wide variety of pediatric and adult conditions (https://myriadrbm.com/wp-content/themes/ howes-child-rbm/includes/pdf.bibliography.php). Examples include identification of protein combinations that can discriminate bacterial from viral or misdiagnosed malaria in children presenting with a respiratory syndrome (11), identification of a multibiomarker disease activity score that can predict radiographic damage progression in rheumatoid arthritis (12), and integration of multiplex immunohistochemistry assays with genome-wide association studies and mass cytometry as tools to understand the basic biology and predict treatment benefit for cancers (13). To begin with the identification of potential biomarkers warranting further study in HGPS, we performed a prospective study of plasma proteins after only 1 year of lonafarnib therapy using a commercial multiplex, microsphere-based immunofluorescent assay.

\section{METHODS}

\section{Study Approvals}

This study was approved by the Institutional Review Boards of Hasbro Children's Hospital, Providence, RI, and Boston Children's Hospital, Boston, MA. Blood samples from children with HGPS were obtained as part of exploratory outcomes during a single-arm clinical trial administering the protein farnesyltransferase inhibitor lonafarnib, registered with Clinicaltrials.gov (NCT00916747) (9), entitled "Phase II Trial of Lonafarnib (a Farnesyltransferase Inhibitor) for Progeria".

\section{Study Groups}

Patients were 3 years of age and older with clinically and genetically confirmed c.1824 C> T, p. Gly608Gly classic HGPS, and adequate organ and marrow function. Consents were translated into the parent(s)' primary language and discussions were performed with interpreters. Assent was obtained from children old enough to comprehend. Twenty-four children with HGPS, an estimated $10 \%$ of the world's population at the time, donated blood at Boston Children's Hospital. Thirty-four healthy pediatric control children donated blood at Hasbro Children's Hospital after they and/or their parents gave informed consent. Healthy children who matched at least one HGPS child by age ( \pm 6 months) and gender were chosen for the controls; after matching was completed, for every HGPS child there was at least one child of the same age ( \pm 6 months) and gender in the control group.

\section{Lonafarnib Dosage and Administration}

Lonafarnib (Merck \& Co., Kenilworth, NJ, USA) dosing was initiated at $115 \mathrm{mg} / \mathrm{m}^{2}$ before increasing to $150 \mathrm{mg} / \mathrm{m}^{2}$ after a minimum of 4 months' adjustment period. Patients experiencing drug-related grade 3 or 4 toxicity and also not responding to supportive care measures were dose-reduced back to $115 \mathrm{mg} / \mathrm{m}^{2}$. Once reduced, patients were permitted to increase the dose of lonafarnib. Patients received oral lonafarnib either by oral capsule or by liquid suspension dispersed in Ora-Blend SF or Ora-Plus (Perrigan Company, Allegan, MI, USA) for every $12 \pm 2 \mathrm{~h}$. Patients were monitored for liver, kidney, and hematological toxicity each month for the first 3 months, and every 4 months for the duration of the study. Compliance with lonafarnib therapy was tracked using a daily patient log than included time and dose throughout the trial period. Patient logs were collected and verified at each patient visit to the trial site. Lonafarnib was generally well tolerated (9).

\section{Sample Collection and Analysis}

Lidocaine/prilocaine cream (2.5\% EMLA (Astra Pharmaceuticals, LP, Wayne, Pa)) was applied to skin overlying a vein in the antecubital fossa for $60 \mathrm{~min}$ in all children with HGPS. Venipunctures were performed within $5 \mathrm{~min}$ of EMLA removal. Blood was collected into sodium heparin tubes and centrifuged at $4{ }^{\circ} \mathrm{C}$ for $15 \mathrm{~min}$ at $1,500 \mathrm{~g}$; plasma was removed and stored at $-80^{\circ} \mathrm{C}$ before analysis. All blood samples were drawn in the morning and while patients were in a fasting state. For patients on lonafarnib therapy, blood was drawn just before morning therapy dosing, when lonafarnib was at a trough level.

Plasma samples were sent to Myriad Rules-Based Medicine (RBM, Austin, TX) for analysis of 90 analytes using the Human MultiAnalyte Profile (MAP), version 1.6 antigens. The RBM HumanMAP is a commercial validated platform, which measures a battery of proteins, including markers of autoimmunity, infection, cancerrelated, hormones, cytokines, cardiovascular risk, acute phase reactants, and others. Samples were stored at $-80{ }^{\circ} \mathrm{C}$ until tested. They were thawed at room temperature, vortexed, spun at $13,000 \mathrm{~g}$ for $5 \mathrm{~min}$ for clarification and $60 \mu \mathrm{l}$ was removed for MAP analysis into a master microtiter plate. The rest of the process was fully automated per RBM procedures. Using automated pipetting, an aliquot of each sample was introduced into one of the fluorescently labeled capture microsphere multiplexes of the MAP, conjugated to antibodies encoded with unique fluorescent signatures. The beads were incubated with the sample at room temperature for 1 hour and antigens of interest allowed to bind to their targets. Multiplexed cocktails of biotinylated detection reagents for each multiplex were added to the sample followed by the addition of fluorescent reporter molecules, and incubated for an additional hour. Multiplexes were developed using an excess of streptavidin-phycoerythrin solution that was thoroughly mixed into each multiplex and incubated for 1 hour at room temperature. The volume of each multiplexed reaction was reduced by vacuum filtration and the volume was increased by dilution into matrix buffer for analysis. RBM determined analyte concentrations using The Luminex 100 instrument and the resulting data stream was interpreted using proprietary data analysis software developed at Rules-Based Medicine. For each multiplex, both calibrators and controls were included on each microtiter plate. RBM used a unique set of controls with known quantities of the protein of interest to create two sets of eight-point calibrators, which were run in the first and last column of each plate and three-level controls were included in duplicate. Testing results were determined first for the high, medium, and low controls for each multiplex to ensure proper assay performance. Concentrations were determined by fitting to standardized concentration curves using RBM curve-fitting routines. This provided a dynamic concentration range from $\mathrm{fg} / \mathrm{ml}$ to $\mathrm{mg} / \mathrm{ml}$ and intra-assay coefficient of variation and accuracy of $<10 \%$. Data were reported back as concentrations (average of two independent measures) and lower

Table 1. Study Population Demographics

\begin{tabular}{ccc}
\hline $\begin{array}{c}\text { Control } \\
(N=34)\end{array}$ & $\begin{array}{c}\text { HGPS pre- } \\
\text { treatment }(N=24)\end{array}$ & $\begin{array}{c}\text { HGPS post- } \\
\text { treatment }^{\mathrm{a}}(N=23)\end{array}$ \\
\hline
\end{tabular}

\begin{tabular}{llll}
\hline Gender & & & \\
Male (\%) & $15(44.1)$ & $10(41.7)$ & $10(43.5)$ \\
Female (\%) & $19(55.9)$ & $14(58.3)$ & $13(56.5)$
\end{tabular}

\begin{tabular}{llcl} 
Age (years) & & & \\
Range & $2.8-17.0$ & $3.1-16.2$ & $4.1-17.2$ \\
Mean $\pm S D$ & $8.9 \pm 3.7$ & $7.42 \pm 3.2$ & $8.4 \pm 3.2$ \\
\hline
\end{tabular}

HGPS, Hutchinson-Gilford Progeria Syndrome.

aTesting occurred after 1 year of lonafarnib therapy. 


\section{Articles | Gordon et al.}

assay limits (lowest level of quantification, LLOQ). The plasma range was determined based on the testing of $\sim 100$ apparently healthy individuals. No assumption was made about the samples having a normal distribution. The range comprises the middle 95\%, with the highest and lowest $2.5 \%$ of the samples excluded for each given assay. RBM MAP technology meets Clinical Laboratory Standard Institute standards.

\section{Statistical Analysis}

Descriptive statistics included the mean and SD for continuous variables, and counts and percentages for categorical variables. Assessment of the significance of linear trends in protein across age was assessed using simple linear regression separately for (i) healthy controls; (ii) lonafarnib-treated HGPS patients at baseline (before receiving lonafarnib); and (iii) lonafarnib-treated HGPS patients after 1 year of treatment with lonafarnib. The significance of the difference between healthy controls' mean protein and pretreatment lonafarnib patients' mean protein, and the difference between healthy controls' mean protein and post-treatment lonafarnib patients' mean protein were assessed using analysis of covariance adjusting for age. Group-by-age interaction was also assessed using analysis of covariance. $P$ values presented are two-sided and are considered significant at the 0.05 level for direct measures and at the 0.1 level for interactions. There is no adjustment for multiple comparisons, given the exploratory nature of this analysis. All

Table 2. Plasma protein concentrations significantly lower in children with HGPS compared with healthy controls $s^{\mathrm{a}, \mathrm{b}}$

\begin{tabular}{|c|c|c|c|c|c|}
\hline Protein & $\begin{array}{l}\text { Control (mean } \pm S D ; \\
\quad N=34)\end{array}$ & $\begin{array}{l}\text { HGPS untreated } \\
(\text { mean } \pm S D ; N=24)\end{array}$ & $\begin{array}{l}\text { Age-adjusted } \\
P \text { value }\end{array}$ & $\begin{array}{l}\text { HGPS treated } \\
(\text { mean } \pm S D ; N=23)\end{array}$ & $\begin{array}{l}\text { Age-adjusted } \\
P \text { value }\end{array}$ \\
\hline \multicolumn{6}{|c|}{ Proteins that did not normalize with treatment } \\
\hline${ }^{\mathrm{c} A d i p o n e c t i n}(\mu \mathrm{g} / \mathrm{ml})(16)$ & $5.54 \pm 1.8$ & $2.56 \pm 1.68$ & $<0.001$ & $2.72 \pm 1.69$ & $<0.001$ \\
\hline $\begin{array}{l}\text { Epithelial-derived neutrophil- } \\
\text { activating protein } 78(\mathrm{ng} / \mathrm{ml})\end{array}$ & $0.36 \pm 0.18$ & $0.20 \pm 0.17$ & $<0.001$ & $0.16 \pm 0.13$ & $<0.001$ \\
\hline Fibrinogen (mg/ml) & $2.81 \pm 0.55$ & $1.86 \pm 0.65$ & $<0.001$ & $1.93 \pm 0.75$ & $<0.001$ \\
\hline $\begin{array}{l}\text { Vascular cell adhesion molecule-1 } \\
\text { (ng/ml) }\end{array}$ & $679.29 \pm 135.34$ & $495.75 \pm 128.17$ & $<0.001$ & $489.82 \pm 112.64$ & $<0.001$ \\
\hline von Willebrand Factor $(\mu \mathrm{g} / \mathrm{ml})$ & $15.69 \pm 6.83$ & $7.80 \pm 4.99$ & $<0.001$ & $9.69 \pm 6.48$ & 0.002 \\
\hline CD40 (ng/ml) & $0.67 \pm 0.15$ & $0.56 \pm 0.14$ & 0.001 & $0.55 \pm 0.12$ & 0.002 \\
\hline 'Leptin (ng/ml) $(9,18)$ & $5.54 \pm 6.72$ & $0.49 \pm 0.32$ & 0.001 & $0.33 \pm 0.23$ & 0.001 \\
\hline $\begin{array}{l}\text { Macrophage-derived chemokine } \\
(\mathrm{pg} / \mathrm{ml})\end{array}$ & $376.6 \pm 120.6$ & $330.7 \pm 98.5$ & 0.002 & $271.65 \pm 90.0$ & $<0.001^{\mathrm{c}}$ \\
\hline Tumor necrosis factor-RII (ng/ml) & $4.00 \pm 1.52$ & $2.92 \pm 1.04$ & 0.003 & $2.87 \pm 1.14$ & 0.004 \\
\hline $\begin{array}{l}\text { Brain-derived neurotrophic factor } \\
(\mathrm{ng} / \mathrm{ml})\end{array}$ & $0.60 \pm 0.29$ & $0.37 \pm 0.44$ & 0.006 & $0.28 \pm 0.26$ & $<0.001$ \\
\hline Interleukin-16 (pg/ml) & $405.56 \pm 190.61$ & $301.86 \pm 90.40$ & 0.007 & $256.83 \pm 71.38$ & $<0.001$ \\
\hline $\begin{array}{l}\text { Extracellular receptor for } \\
\text { advanced glycation end products } \\
\text { (ng/ml) }\end{array}$ & $14.87 \pm 12.58$ & $7.41 \pm 2.93$ & 0.010 & $9.73 \pm 6.00$ & 0.082 \\
\hline Interleukin-3 (ng/ml) & $0.31 \pm 0.11$ & $0.24 \pm 0.08$ & 0.015 & $0.26 \pm 0.07$ & 0.049 \\
\hline Myoglobin (ng/ml) & $7.28 \pm 3.76$ & $5.78 \pm 2.42$ & 0.035 & $6.32 \pm 2.25$ & 0.235 \\
\hline Interleukin-1 alpha (ng/ml) & $0.01 \pm 0.003$ & $0.01 \pm 0.004$ & 0.043 & $0.01 \pm 0.004$ & 0.199 \\
\hline
\end{tabular}

HGPS, Hutchinson-Gilford Progeria Syndrome.

asections are presented in order of ascending $P$ values for control vs. HGPS untreated.

${ }^{\mathrm{b}}$ Table does not include interleukin-1ra due to a significant group-by-age interaction (i.e., magnitude and direction of the difference in means between groups depended on patient age). Table does include adiponectin, which also shows a significant group-by-age interaction, the direction of the difference in means between groups was consistent across patient age (Tables 4 and $\mathbf{5}$ ).

cPreviously measured in untreated HGPS patients using a clinical assay. 


\section{Abnormal plasma proteins in progeria Articles}

statistical analyses were carried out using SAS version 9.3. Pearson correlation values were between the proteins and patient age.

\section{RESULTS}

Table 1 summarizes demographics. Plasma samples from 24 lonafarnib-treated children with HGPS, age range of 3.1-16.2 years, were analyzed at pre-therapy baseline and again after 1 year of daily oral lonafarnib therapy, as described previously (9). One patient died after 4 months of therapy and was not included in the on-therapy sample group $(N=23)$. Healthy untreated non-HGPS control children were similarly analyzed $(N=34)$.

Supplementary Table S1 (online) lists the 90 proteins present in the assay, along with the least detectible dose for each protein. Of these, 23 proteins yielded values below the least detectible dose for at least $80 \%$ of the samples in each of the three patient sample categories, and one (interleukin (IL)15) did so for at least $70 \%$ of the samples; these proteins are not included in the analyses presented here. Without treatment, the mean values for 23/66 (34.8\%) proteins were significantly lower in HGPS compared with those in controls (Table 2), and $7 / 66(10.6 \%)$ were significantly higher (Table 3; age-adjusted $P \leq 0.05$ ). Of these, six proteins whose levels were initially abnormally low in the untreated HGPS group normalized with lonafarnib therapy: ILs $1 \alpha, 7$, and 13 (IL-1 $\alpha$, IL-7, IL-13), beta-2 microglobulin, C-reactive protein, and myoglobin (Table 2). Of the seven proteins whose means were significantly larger in untreated HGPS vs. controls, only alpha-2 macroglobulin normalized with lonafarnib therapy (Table 3).

There were 36 proteins that significantly increased or decreased with patient age (Table 4) for at least one of the three groups (healthy controls, HGPS patients before treatment, and/or HGPS patients after lonafarnib treatment). Correlation values between 0.2 and 0.6 were considered moderate and those at or above 0.6 were considered strong.

Table 5 displays the proteins for which a significant groupby-age interaction existed (i.e., for which the differences between HGPS, treated or untreated, vs. controls differed as age increased). Of the 36 proteins in Table 4, 17 are also in Table 5. Four proteins are of particular interest, despite the significant interaction of groupings with age: their means in treated and untreated HGPS significantly differed from controls across the age range tested (Tables 2 and 3); they also decrease (adiponectin) or increase (creatine kinase $\mathrm{MB}$, eotaxin, insulin) with increasing patient age in HGPS, but not in controls (Table 5). For adiponectin, eotaxin, and insulin, the differences between HGPS and controls became more pronounced with increasing patient age. Creatine kinase $\mathrm{MB}$ is detectable in only $12 \%$ of controls and $35.7 \%$ of HGPS samples, but those samples with detectable levels fall within the plasma normal range for this assay, at or below $1.1 \mathrm{ng} / \mathrm{ml}$, indicating no increased cardiac or skeletal muscle damage (14). Although carcinoembryonic antigen, IL-1ra, and macrophage-derived chemokine levels are significantly different between HGPS patients (treated and untreated) vs. controls on average, their regression lines vs. age intersect with controls indicating the difference vs. control is not consistent across the age range; also results need to be interpreted with caution for this protein, given that many patients were below the least detectible dose. For 10 additional proteins listed in Table 5, patients with HGPS (treated or untreated) do not appear different from controls on average even in the presence of significant group-by-age interactions.

There were five proteins (CD40 ligand, ferritin, thyroxinebinding globulin, IL-8, and tumor necrosis factor alpha (TNF-alpha)) whose plasma levels for untreated patients with HGPS were similar to controls, but subsequently became abnormal with treatment when compared with controls

Table 3. Plasma protein concentrations significantly greater in children with HGPS compared with healthy controls ${ }^{a}$

\begin{tabular}{|c|c|c|c|c|c|}
\hline Protein & $\begin{array}{l}\text { Control (mean } \pm S D ; \\
\qquad N=34)\end{array}$ & $\begin{array}{l}\text { HGPS untreated } \\
(\text { mean } \pm S D ; N=24)\end{array}$ & $\begin{array}{l}\text { Age-adjusted } \\
P \text { value }\end{array}$ & $\begin{array}{l}\text { HGPS treated (mean } \pm S D ; \\
\qquad N=23 \text { ) }\end{array}$ & $\begin{array}{l}\text { Age-adjusted } \\
P \text { value }\end{array}$ \\
\hline \multicolumn{6}{|c|}{ Proteins that did not normalize with treatment } \\
\hline Complement 3 (mg/ml) & $0.87 \pm 0.13$ & $1.00 \pm 0.16$ & $<0.001$ & $0.96 \pm 0.15$ & 0.017 \\
\hline ansulin $(\mu \mathrm{lU} / \mathrm{ml})(5,18)$ & $2.56 \pm 1.29$ & $9.03 \pm 15.85$ & $0.005^{c}$ & $5.04 \pm 6.60$ & $0.014^{c}$ \\
\hline Eotaxin $(\mathrm{pg} / \mathrm{ml})$ & $367.01 \pm 145.34$ & $477.29 \pm 186.50$ & $0.011^{c}$ & $570.52 \pm 193.72$ & $<0.001^{c}$ \\
\hline Cancer antigen 19-9 (U/ml) & $9.74 \pm 13.09$ & $19.29 \pm 16.27$ & 0.027 & $17.92 \pm 13.97$ & 0.034 \\
\hline $\begin{array}{l}\text { Carcinoembryonic antigen } \\
(\mathrm{ng} / \mathrm{ml})\end{array}$ & $1.11 \pm 0.64$ & $1.87 \pm 1.54$ & 0.038 & $1.77 \pm 1.39$ & $0.024^{c}$ \\
\hline Creatine kinase MB (ng/ml) & $0.44 \pm 0.05$ & $0.53 \pm 0.21$ & $0.047^{c}$ & $0.55 \pm 0.21$ & 0.005 \\
\hline \multicolumn{6}{|c|}{ Proteins that normalized with treatment } \\
\hline $\begin{array}{l}\text { Alpha-2 macroglobulin (mg/ } \\
\mathrm{ml} \text { ) }\end{array}$ & $0.81 \pm 0.08$ & $0.85 \pm 0.98$ & 0.050 & $0.84 \pm 0.12$ & 0.194 \\
\hline $\begin{array}{l}\text { HGPS, Hutchinson-Gilford Progeria Sy } \\
{ }^{\text {a }} \text { Sections are presented in order of a } \\
\text { bPreviously validated in untreated } \mathrm{HG} \\
{ }^{\mathrm{C}} \text { Age interaction was significant, } P \leq 0\end{array}$ & $\begin{array}{l}\text { ding } P \text { values for contro } \\
\text { atients using a clinical }\end{array}$ & S untreated. & & & \\
\hline
\end{tabular}




\section{Articles | Gordon et al.}

Table 4. Correlations vs. age for proteins where significant trend with age was detected

\begin{tabular}{|c|c|c|c|}
\hline Protein & $\begin{array}{l}\text { Healthy } \\
\text { control slope } \\
(P \text { value })\end{array}$ & $\begin{array}{l}\text { Untreated } \\
\text { HGPS slope } \\
\text { ( } P \text { value })\end{array}$ & $\begin{array}{c}\text { Lonafarnib- } \\
\text { treated HGPS } \\
\text { slope ( } P \text { value) }\end{array}$ \\
\hline \multicolumn{4}{|c|}{ Decrease with age in HGPS untreated ${ }^{a}$ and treated, but not in controls } \\
\hline badiponectin(16) & $0.13(0.5)$ & $\begin{array}{c}-0.73 \\
(<0.001)\end{array}$ & $-0.56(0.005)$ \\
\hline b Leptin $(9,18)$ & $0.18(0.32)$ & $-0.56(0.004)$ & $-0.39(0.07)$ \\
\hline Interleukin-10 & $-0.10(0.58)$ & $-0.42(0.04)$ & $-0.37(0.09)$ \\
\hline Interleukin-16 & $-0.19(0.28)$ & $-0.40(0.05)$ & $-0.49(0.02)$ \\
\hline \multicolumn{4}{|c|}{ Decrease with age in HGPS untreated ${ }^{a}$, but not in controls or HGPS treated } \\
\hline $\begin{array}{l}\text { Epithelial-derived neutrophil- } \\
\text { activating protein } 78\end{array}$ & $-0.22(0.22)$ & $-0.47(0.02)$ & $-0.12(0.58)$ \\
\hline $\begin{array}{l}\text { Macrophage inflammatory } \\
\text { protein-1 beta }\end{array}$ & $\begin{array}{l}-0.09 \\
(0.613)\end{array}$ & $-0.42(0.04)$ & $0.04(0.85)$ \\
\hline Matrix metalloproteinase-3 & $0.27(0.12)$ & $-0.41(0.05)$ & $-0.27(0.21)$ \\
\hline \multicolumn{4}{|c|}{ Decrease with age in HGPS treated ${ }^{\text {a }}$, but not in controls or HGPS untreated } \\
\hline Prostatic acid phosphatase & $0.07(0.70)$ & $-0.01(0.97)$ & $-0.50(0.02)$ \\
\hline Thyroid-stimulating hormone & $-0.25(0.15)$ & $-0.31(0.14)$ & $-0.39(0.06)$ \\
\hline \multicolumn{4}{|c|}{ Increase with age in HGPS untreated ${ }^{\mathrm{a}}$ and treated, but not in controls } \\
\hline Apolipoprotein CIII & $0.24(0.16)$ & $0.69(<0.001)$ & $0.67(<0.001)$ \\
\hline Factor VII & $-0.27(0.12)$ & $0.53(0.008)$ & $0.50(0.02)$ \\
\hline $\begin{array}{l}\text { Plasminogen activator } \\
\text { inhibitor-1 }\end{array}$ & $0.10(0.57)$ & $0.42(0.04)$ & $0.54(0.007)$ \\
\hline Eotaxin & $-0.08(0.64)$ & $0.36(0.08)$ & $0.40(0.06)$ \\
\hline \multicolumn{4}{|c|}{ Increase with age in HGPS untreated ${ }^{\text {a }}$, but not in controls or HGPS treated } \\
\hline Serum amyloid $\mathrm{P}$ & $0.19(0.27)$ & $0.52(0.009)$ & $-0.13(0.54)$ \\
\hline Haptoglobin & $0.16(0.38)$ & $0.42(0.04)$ & $0.03(0.88)$ \\
\hline Immunoglobulin $\mathrm{E}$ & $0.00(0.99)$ & $0.41(0.05)$ & $0.17(0.44)$ \\
\hline Complement 3 & $0.00(0.99)$ & $0.38(0.06)$ & $0.04(0.85)$ \\
\hline \multicolumn{4}{|c|}{ Decrease with age in controls, but not in HGPS untreated or treated } \\
\hline Interleukin-18 & $\begin{array}{c}-0.58 \\
(<0.001)\end{array}$ & $-0.27(0.20)$ & $-0.18(0.41)$ \\
\hline $\begin{array}{l}\text { Intercellular adhesion } \\
\text { molecule-1 }\end{array}$ & $\begin{array}{l}-0.50 \\
(0.003)\end{array}$ & $0.14(0.52)$ & $-0.16(0.45)$ \\
\hline Tumor necrosis factor alpha & $-0.32(0.07)$ & $-0.25(0.24)$ & $-0.28(0.20)$ \\
\hline Alpha fetoprotein & $-0.30(0.08)$ & $-0.05(0.80)$ & $-0.26(0.23)$ \\
\hline Growth hormone & $-0.30(0.09)$ & $-0.02(0.92)$ & $0.03(0.90)$ \\
\hline Interleukin-1ra & $-0.30(0.08)$ & $0.18(0.39)$ & $0.03(0.90)$ \\
\hline \multicolumn{4}{|c|}{ Decrease with age in controls ${ }^{a}$, HGPS untreated, and HGPS treated } \\
\hline $\begin{array}{l}\text { Macrophage-derived } \\
\text { chemokine }\end{array}$ & $\begin{array}{c}-0.73 \\
(<0.001)\end{array}$ & $-0.43(0.03)$ & $-0.37(0.08)$ \\
\hline $\begin{array}{l}\text { Sex hormone-binding } \\
\text { globulin }\end{array}$ & $\begin{array}{l}-0.48 \\
(0.004)\end{array}$ & $\begin{array}{l}-0.76 \\
(<0.001)\end{array}$ & $-0.71(<0.001)$ \\
\hline
\end{tabular}




\begin{tabular}{|c|c|c|c|}
\hline Protein & $\begin{array}{l}\text { Healthy } \\
\text { control slope } \\
\text { ( } P \text { value })\end{array}$ & $\begin{array}{l}\text { Untreated } \\
\text { HGPS slope } \\
\text { ( } P \text { value })\end{array}$ & $\begin{array}{l}\text { Lonafarnib- } \\
\text { treated HGPS } \\
\text { slope ( } P \text { value) }\end{array}$ \\
\hline \multicolumn{4}{|c|}{ Decrease with age in controls ${ }^{\mathrm{a}}$, HGPS treated but not HGPS untreated } \\
\hline Carcinoembryonic antigen & $-0.36(0.04)$ & $\begin{array}{c}-0.33, P>0.1 \\
(0.11)\end{array}$ & $-0.44(0.04)$ \\
\hline \multicolumn{4}{|c|}{ Decrease with age in controls ${ }^{\mathrm{a}}$, HGPS untreated, but not HGPS treated } \\
\hline Stem cell factor & $-0.42(0.01)$ & $-0.50(0.01)$ & $-0.11(0.62)$ \\
\hline T-cell-specific protein RANTES & $-0.39(0.02)$ & $-0.36(0.08)$ & $-0.09(0.69)$ \\
\hline CD40 ligand & $-0.34(0.05)$ & $-0.41(0.05)$ & $-0.07(0.74)$ \\
\hline Creatine kinase $M B$ & $-0.33(0.06)$ & $-0.54(0.006)$ & $-0.32(0.14)$ \\
\hline Interleukin-1alpha & $-0.30(0.08)$ & $-0.57(0.004)$ & $-0.24(0.27)$ \\
\hline CD40 & $-0.29(0.09)$ & $-0.36(0.080)$ & $0.11(0.62)$ \\
\hline
\end{tabular}

Increase with age in both controls, HGPS untreated ${ }^{\text {a }}$, and HGPS treated

Insulin-like growth factor-1(5) $0.52(0.002)$

Immunoglobulin A(5)

$0.37(0.03)$

Insulin $(5,18)$
$0.42(0.01)$

$$
\begin{gathered}
0.76(<0.001) \\
0.66(<0.001) \\
0.47(0.02)
\end{gathered}
$$

$0.62(0.002)$

$0.62(0.002)$

$0.56(0.006)$

Increase with age in both controls and HGPS untreated, but not HGPS treated

Ferritin

$0.31(0.07)$

$0.40(0.05)$

$0.09(0.70)$

HGPS, Hutchinson-Gilford Progeria Syndrome.

apresented in order of decreasing correlation strength as per this patient group, regardless of positive or negative value.

bPreviously demonstrated in untreated HGPS patients using a clinical assay.

(Supplementary Table S2. We speculate that lonafarnib affects these proteins regardless of disease state, although there were no lonafarnib-treated non-HGPS samples available. There were 30 detectable proteins whose means for patients with HGPS were similar between untreated and treated HGPS samples when compared with controls (Table 6).

Several proteins are of particular interest because their means are significantly lower in HGPS (treated and untreated groups) than controls regardless of age (no significant groupby-age interaction: apolipoprotein A1 (Apo-A1), brain derived neurotrophic factor (BDNF), CD40, epithelialderived neutrophil-activating protein 78 (ENA-78), extracellular receptor for advanced glycation end products (ENRAGE), fibrinogen, IL-3, IL-16, leptin, myeloperoxidase (MPO), tumor necrosis factor (TNF) receptor 2 (TNF-RII), $\mathrm{C}-\mathrm{C}$ motif chemokine ligand 5 (RANTES), stem cell factor, von Willebrand Factor (vWF), and vascular cell adhesion molecule-1 (VCAM-1)) or greater than controls (cancer antigen 19-9 and complement 3), regardless of age (Figure 1 and Supplementary Figure S1.

\section{DISCUSSION}

There is a paucity of validated disease-relevant biomarkers that can be utilized as indicators of disease status and treatment response for children with HGPS. This is the first multi-analyte study of plasma proteins for this disease. It seeks to open an avenue for biomarker discovery. Similar exploratory biomarker studies on this assay platform have been performed for diseases such as facioscapulohumeral muscular dystrophy (15) and chronic obstructive pulmonary disease (16). Within the 90 proteins surveyed, there was a subset of ILs and several other proteins that were lower than controls at baseline, and normalized with treatment: IL- $1 \alpha$, IL-7, IL-13, as well as beta-2 microglobulin, C-reactive protein, and myoglobin. Alpha-2 microglobulin was elevated and normalized with treatment. There were 15 proteins whose levels were lower than controls at baseline and did not change with treatment, but have not previously been identified as abnormal in HGPS: Apo-A1, BDNF, CD40, ENA-78, ENRAGE, fibrinogen, IL-3, IL-16, MDC, MPO, RANTES, stem cell factor, TNF-RII, VCAM- 1, and vWF. Conversely, there were five proteins that were elevated over controls at baseline and did not change with treatment, but have not previously been identified as being abnormal in HGPS: cancer antigen 19-9, creatine kinase MB, carcinoembryonic antigen, complement 3 , and eotaxin.

For a number of proteins whose means significantly differed from controls, age also influenced plasma levels. Eotaxin and insulin increased, and adiponectin decreased with increasing patient age in HGPS, but not in controls. The fact that these proteins had trend lines for HGPS that did not intersect with 


\section{Articles | Gordon et al.}

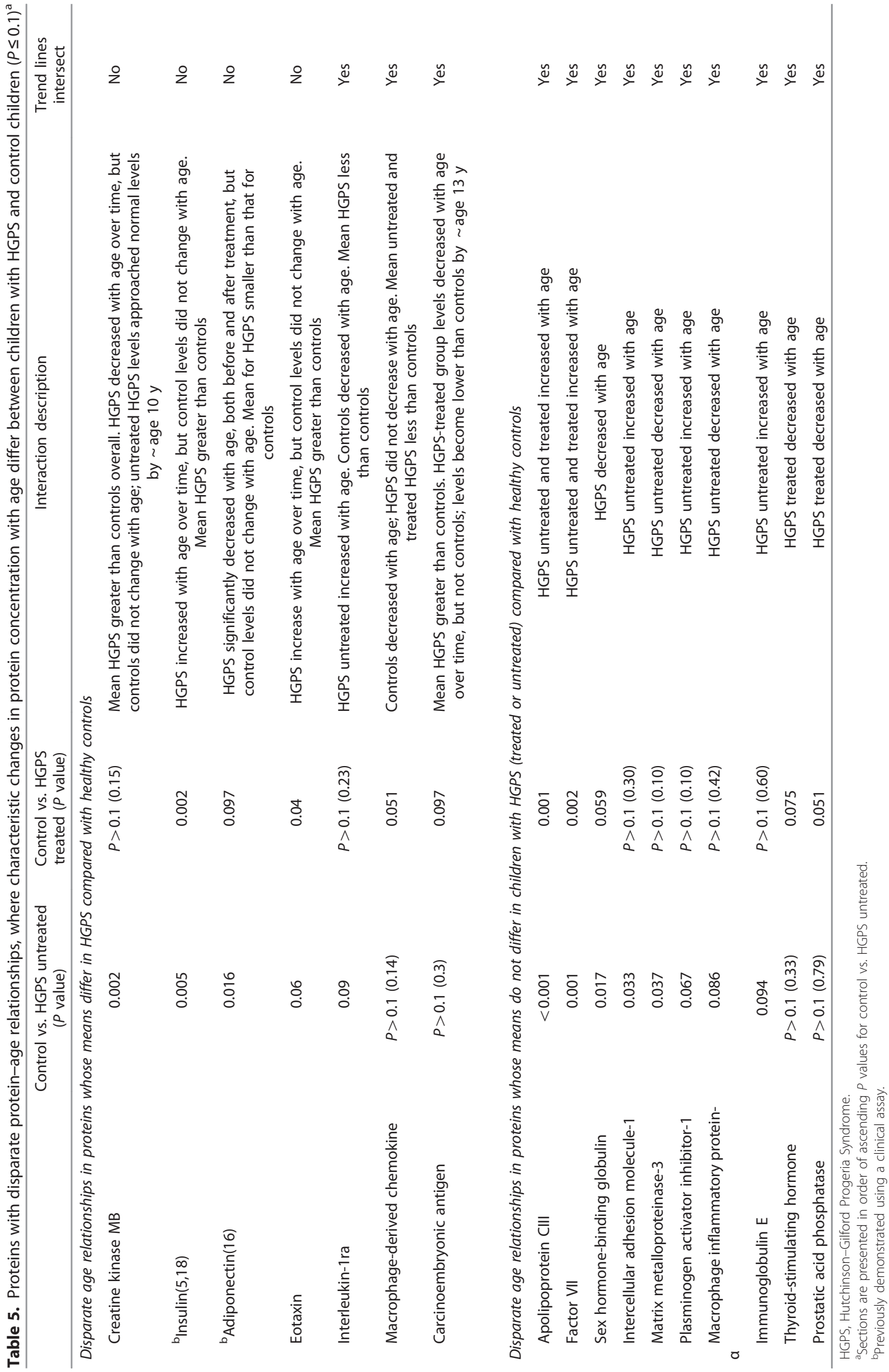


Table 6. Thirty proteins with similar levels in plasma of children with HGPS and healthy controls $(P>0.05)^{\mathrm{a}}$

\begin{tabular}{|c|c|c|c|c|c|}
\hline Protein & $\begin{array}{l}\text { Control (mean } \pm S D ; \\
\qquad N=34)\end{array}$ & $\begin{array}{l}\text { HGPS untreated } \\
\text { (mean } \pm S D ; N=24)\end{array}$ & $\begin{array}{l}\text { Age-adjusted } \\
P \text { value }\end{array}$ & $\begin{array}{c}\text { HGPS-treated } \\
(\text { mean } \pm S D ; N=23)\end{array}$ & $\begin{array}{l}\text { Age-adjusted } \\
P \text { value }\end{array}$ \\
\hline Haptoglobin (mg/ml) & $0.90 \pm 0.53$ & $1.17 \pm 0.76$ & 0.053 & $1.22 \pm 0.91$ & 0.102 \\
\hline $\begin{array}{l}\text { Granulocyte colony-stimulating } \\
\text { factor }(\mathrm{pg} / \mathrm{ml})\end{array}$ & $18.47 \pm 21.14$ & $10.19 \pm 8.87$ & 0.073 & $15.25 \pm 17.83$ & 0.508 \\
\hline Interleukin-10 (pg/ml) & $17.85 \pm 5.62$ & $16.0 \pm 1.6$ & 0.089 & $16.04 \pm 1.14$ & 0.122 \\
\hline Interleukin-18 (pg/ml) & $240.09 \pm 91.25$ & $335.47 \pm 226.99$ & 0.089 & $301.37 \pm 147.78$ & 0.072 \\
\hline Cancer antigen $125(\mathrm{U} / \mathrm{ml})$ & $11.38 \pm 6.56$ & $16.39 \pm 12.93$ & 0.090 & $13.39 \pm 6.7$ & 0.310 \\
\hline Interleukin-4 (pg/ml) & $171.32 \pm 55.43$ & $151.88 \pm 46.04$ & 0.096 & $166.65 \pm 59.57$ & 0.716 \\
\hline Immunoglobulin $E$ (ng/ml) & $90.65 \pm 248.23$ & $190.69 \pm 282.59$ & $0.108^{b}$ & $136.33 \pm 189.37$ & 0.445 \\
\hline Alpha-1 Antitrypsin (mg/ml) & $2.44 \pm 0.46$ & $2.25 \pm 0.40$ & 0.119 & $2.33 \pm 0.42$ & 0.332 \\
\hline Lipoprotein A ( $\mu \mathrm{g} / \mathrm{ml})$ & $79.98 \pm 80.84$ & $48.27 \pm 68.33$ & 0.137 & $45.47 \pm 76.37$ & 0.116 \\
\hline $\begin{array}{l}\text { Sex hormone-binding globulin } \\
(\mathrm{nmol} / \mathrm{l})\end{array}$ & $70.17 \pm 29.85$ & $67.48 \pm 38.35$ & $0.148^{b}$ & $65.17 \pm 36.34$ & $0.289^{b}$ \\
\hline Prostatic acid phosphatase (ng/ml) & $0.20 \pm 0.08$ & $0.23 \pm 0.07$ & 0.151 & $0.20 \pm 0.07$ & $0.908^{b}$ \\
\hline Matrix metalloproteinase-3 (ng/ml) & $0.86 \pm 0.63$ & $0.65 \pm 0.32$ & $0.208^{b}$ & $0.63 \pm 0.25$ & 0.118 \\
\hline Immunoglobulin A(5)(mg/ml) & $0.83 \pm 0.45$ & $0.62 \pm 0.39$ & 0.210 & $0.74 \pm 0.43$ & 0.557 \\
\hline $\begin{array}{l}\text { Intercellular adhesion molecule-1 } \\
\text { (ng/ml) }\end{array}$ & $137.8 \pm 27.82$ & $151.54 \pm 37.78$ & $0.213^{b}$ & $140.01 \pm 29.58$ & 0.930 \\
\hline $\begin{array}{l}\text { Tissue inhibitor of } \\
\text { metalloproteinases } 1 \text { ( } \mathrm{ng} / \mathrm{ml})\end{array}$ & $54.67 \pm 8.19$ & $49.90 \pm 14.81$ & 0.232 & $48.68 \pm 15.12$ & 0.072 \\
\hline $\begin{array}{l}\text { Vascular endothelial growth factor } \\
(\mathrm{pg} / \mathrm{ml})\end{array}$ & $370.85 \pm 102.43$ & $337.87 \pm 107.78$ & 0.280 & $347.35 \pm 115.09$ & 0.449 \\
\hline Apolipoprotein CIII ( $\mu \mathrm{g} / \mathrm{ml})$ & $68.36 \pm 20.95$ & $71.23 \pm 55.41$ & $0.293^{b}$ & $59.21 \pm 42.71$ & $0.367^{c}$ \\
\hline $\begin{array}{l}\text { Serum glutamic oxaloacetic } \\
\text { transaminase }(\mu \mathrm{g} / \mathrm{ml})\end{array}$ & $8.36 \pm 2.96$ & $7.66 \pm 1.63$ & 0.323 & $8.52 \pm 2.54$ & 0.848 \\
\hline $\begin{array}{l}{ }^{d} \text { Thyroid-stimulating hormone(5) } \\
(\mu \mathrm{UU} / \mathrm{ml})\end{array}$ & $2.13 \pm 0.67$ & $2.46 \pm 1.24$ & 0.381 & $2.19 \pm 1.85$ & $0.992^{b}$ \\
\hline $\begin{array}{l}\text { Macrophage inflammatory protein- } \\
1 \text { beta }(\mathrm{pg} / \mathrm{ml})\end{array}$ & $129.04 \pm 37.85$ & $126.03 \pm 32.16$ & 0.533 & $135.29 \pm 59.75$ & 0.645 \\
\hline $\begin{array}{l}\text { Monocyte chemoattractant protein- } \\
1(\mathrm{pg} / \mathrm{ml})\end{array}$ & $335.53 \pm 126.58$ & $361.88 \pm 100.3$ & 0.540 & $376.39 \pm 130.63$ & 0.274 \\
\hline Insulin-like growth factor-1 (ng/ml) & $179.44 \pm 143.31$ & $130.63 \pm 109.47$ & 0.566 & $135.32 \pm 127.62$ & 0.302 \\
\hline $\begin{array}{l}\text { Macrophage inflammatory protein-1 } \\
\text { alpha }(\mathrm{pg} / \mathrm{ml})\end{array}$ & $47.84 \pm 13.96$ & $45.72 \pm 10.36$ & $0.613^{b}$ & $41.4 \pm 8.42$ & 0.064 \\
\hline $\begin{array}{l}\text { Plasminogen activator inhibitor-1 } \\
(\mathrm{ng} / \mathrm{ml})\end{array}$ & $15.18 \pm 8.98$ & $15.18 \pm 14.38$ & $0.698^{b}$ & $13.14 \pm 8.12$ & 0.462 \\
\hline Alpha fetoprotein (ng/ml) & $1.86 \pm 1.73$ & $2.13 \pm 1.99$ & 0.808 & $1.78 \pm 1.77$ & 0.740 \\
\hline Apolipoprotein $\mathrm{H}(\mu \mathrm{g} / \mathrm{ml})$ & $182.49 \pm 46.73$ & $183.35 \pm 42.72$ & 0.867 & $184.71 \pm 34.38$ & 0.817 \\
\hline Serum amyloid $P(\mu \mathrm{g} / \mathrm{ml})$ & $10.88 \pm 3.81$ & $10.31 \pm 3.19$ & 0.901 & $11.16 \pm 5.08$ & 0.793 \\
\hline Growth hormone (ng/ml) & $2.77 \pm 3.11$ & $2.93 \pm 3.68$ & 0.917 & $5.28 \pm 8.25$ & 0.125 \\
\hline Factor VII (ng/ml) & $526.74 \pm 121.5$ & $520.17 \pm 189.15$ & $0.992^{b}$ & $529.78 \pm 173.78$ & $0.904^{c}$ \\
\hline Immunoglobulin $\mathrm{M}(5)(\mathrm{mg} / \mathrm{ml})$ & $0.99 \pm 0.33$ & $0.96 \pm 0.33$ & 0.994 & $0.85 \pm 0.32$ & 0.124 \\
\hline
\end{tabular}

HGPS, Hutchinson-Gilford Progeria Syndrome; TSH, thyroid-stimulating hormone.

aproteins are presented in order of ascending $P$ values for control vs. HGPS-untreated.

${ }^{\mathrm{b}}$ Age interaction was significant, $P<0.1$.

${ }^{c}$ Age interaction was significant, $P<0.001$.

${ }^{\mathrm{d}} \mathrm{TSH}$ previously published as being within normal clinical limits.

control trend lines supports their future investigation as meaningful disease biomarkers in HGPS. In addition, the differences between HGPS and controls became more pronounced with increasing patient age, implying that the abnormality worsens with disease progression. Although carcinoembryonic antigen, IL-1ra, and macrophage-derived 

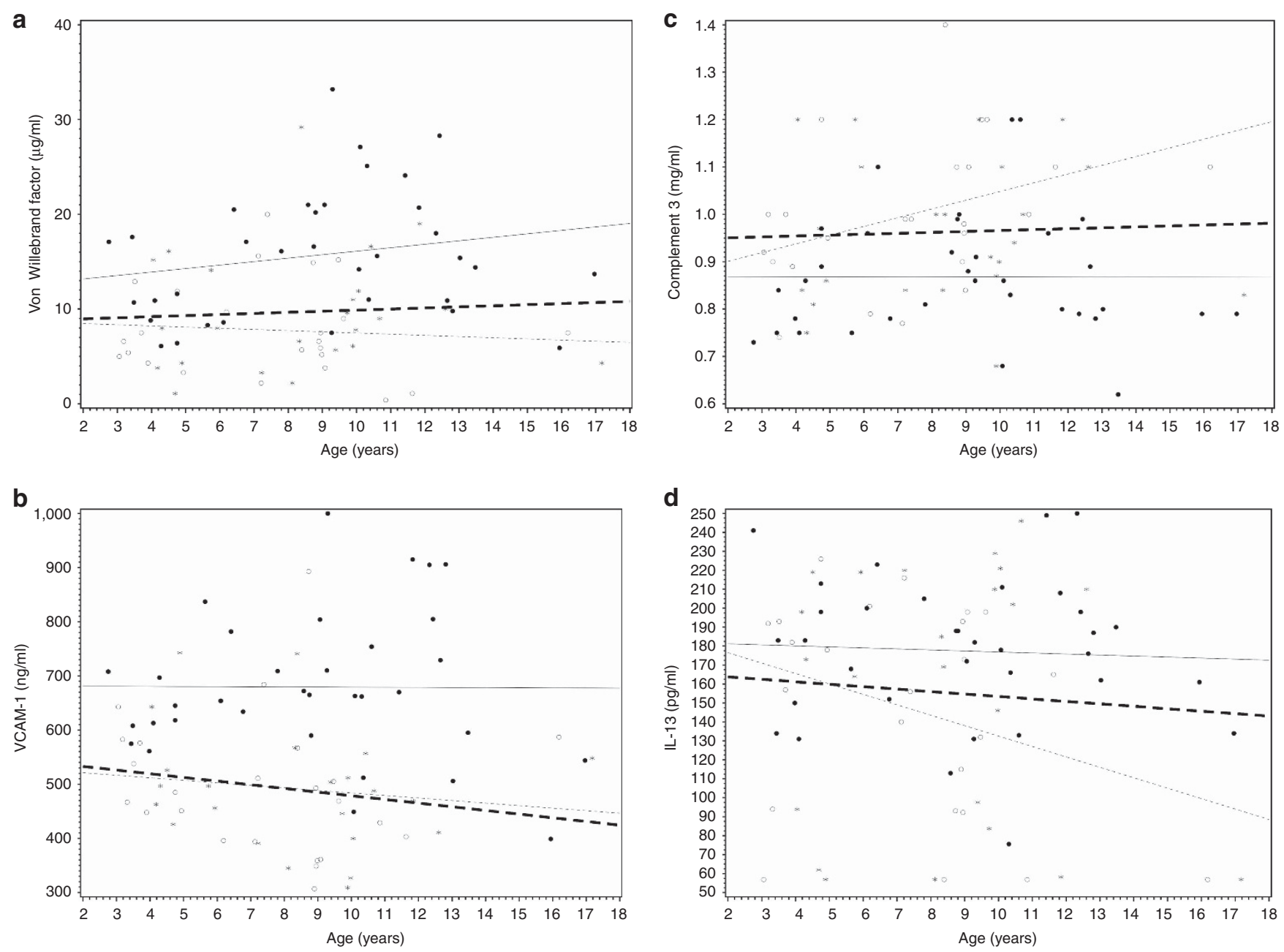

Figure 1. Plots representing various result categories. Symbols are individual patient levels and lines are trend lines. (a,b) Levels of von Willebrand Factor and VCAM-1 are significantly lower in HGPS compared with controls regardless of treatment or age. (c) Levels of complement 3 are increased over controls, and normalize with lonafarnib treatment. (d) Levels of interleukin-13 are decreased compared with controls, and normalize with lonafarnib treatment. Control: Syndrome. ; HGPS Baseline: ○_____ ; HGPS Lonafarnib-treated: * . HGPS, Hutchinson-Gilford Progeria

chemokine levels were significantly different from controls on average, their trend lines with age intersected with controls, diminishing enthusiasm for further exploring them as potential biomarkers. Ten additional proteins listed in Table 5 were not different from controls on average, and also intersected with controls when age trends were plotted, even though there was a significant age interaction. This diminishes our enthusiasm for further exploring them as potential biomarkers.

Several cardiovascular and neurovascular disease-associated proteins not previously identified as abnormal in HGPS are of particular interest for further validation. Elevations in serum alpha-2-macroglobulin levels are associated with high-grade white matter lesions in the general population (17), and increased odds of stroke and deep vein thrombosis in children (18). The fact that this protein was elevated at baseline, but normalized with treatment, adds to its potential value. In addition, levels of vWF were about half of those measured in healthy age- and gender-matched controls, which may constitute a clinically significant finding. Low level or dysfunctional vWF protein results in von Willebrand disease, which typically manifests with mucocutaneous bleeding symptoms such as epistaxis and heavy menstrual bleeding. Although initially recognized for its role in hemostasis, vWF has also been demonstrated to influence angiogenesis. vWF is secreted by vascular endothelial cells and platelets. The potential etiology of low vWF is not clear from the pathogenesis of HGPS. However, the impact of vWF on both intracellular and extracellular pathways regulating angiogenesis could be influenced (19), as there is evidence for both abnormal extracellular matrix $(20,21)$ and endothelial cell involvement in HGPS (22). Another protein of significant interest in the setting of HGPS is Apo-A1. Apo-A1 represents the primary apolipoprotein constituent of HDL particles, and HDL is reduced in HGPS (23). Decreased Apo-A1 is associated with increased coronary events in the general population and poor glycemic control (24). 


\section{Abnormal plasma proteins in progeria Articles}

There are a number of protein abnormalities identified in this study that are associated with cardiovascular disease, neurovascular disease, and dysfunctional glucose metabolism in the general population, including adiponectin, alpha-2 macroglobulin, Apo-A1, BDNF, leptin, and insulin $(25,26)$. In HGPS, it is possible that these abnormalities contribute in a cumulative manner to the characteristic insulin resistance and premature atherosclerosis seen. As with other diseases (27-29), a panel of biomarkers that incorporates these proteins could be extremely valuable if it is predictive of cardiovascular status, stroke events, or survival.

Support for the validity of the results of this study comes from proteins in the assay that have been assessed in HGPS using clinically validated assays as decreased, increased, or similar to the healthy control population, and previously published. For example, we have previously reported that adiponectin was decreased in HGPS, and, unlike controls, decreased significantly with increasing patient age (23). Leptin was detected in controls, and was largely undetectable in HGPS, both untreated and treated groups (9). This correlates with the characteristic extreme paucity of subcutaneous fat in children with HGPS. Lack of subcutaneous fat is likely a major contributor to insulin resistance in HGPS, as reflected in the extremely low levels of proteins secreted mainly by subcutaneous fat cells, including leptin and adiponectin. It is not surprising that these proteins and overall insulin resistance were not improved by treatment with lonafarnib, as the fat compartment was not affected by lonafarnib as measured using dual X-ray absorptiometry (9). Insulin levels were elevated in HGPS and significantly improved with treatment, although they were still elevated over controls, correlating with the insulin resistance detected in HGPS (9). Growth hormone (5,9), IGF-1 (refs 5,9), IgA (5), IgM (5), and TSH (9) values, all published as being within normal limits for healthy individuals, were found to be similar to healthy control levels in this study. Although C-reactive protein has been assessed as normal in HGPS (23), this study found that it was lower in HGPS than in controls at baseline, but not with lonafarnib treatment.

There are several weaknesses that should be addressed in follow-up studies. As this study was exploratory, we did not fully account for multiple comparisons. Instead, we presented the proteins in order of ascending $P$ values or descending correlation strength when comparing controls with untreated HGPS samples, to highlight which proteins may be of greatest interest. Future validation studies will likely be performed with individual proteins, and therefore abrogate the need for this statistical consideration. In addition, when validation studies are performed for individual proteins and protein subsets identified in this exploratory study, it will be necessary to analyze relationships to disease outcomes such as cardiovascular status, neurovascular status, or survival, in order to further evaluate the protein as a disease-relevant biomarker. Finally, control samples were not collected longitudinally, so that within-subject variability for control participants could not be evaluated.

\section{CONCLUSIONS}

To date, no validated FDA-approved circulatory biomarker exists for HGPS. We have identified a set of plasma proteins in children with HGPS, before and 1 year after initiating treatment with the farnesyltransferase inhibitor lonafarnib. This is an initial survey step in identifying serologic biomarkers that may provide insight into the natural history of disease, and/or be indicative of improvements with treatment. This is the first study of HGPS to employ a multi-analyte array platform to identify potential plasma biomarkers in HGPS.

The goal of this study was to make these data available worldwide to the research community studying this ultra-rare disease. This Rules-Based Medicine, HumanMAP panel was not specifically designed for this rare disease, but was utilized as proof-of-principle for this type of approach in biomarker discovery for HGPS. In this nonspecific protein panel, more than $40 \%$ of analyzed proteins differed from the age- and gender-matched control population. This implies that such an approach may have significant potential for identifying meaningful plasma protein biomarkers for children with HGPS. Future studies should focus on essential studies that will further evaluate plasma proteins identified here as having abnormal levels in HGPS, namely validation and clinical disease correlations.

\section{SUPPLEMENTARY MATERIAL}

Supplementary material is linked to the online version of the paper at http://www.nature.com/pr

\section{ACKNOWLEDGMENTS}

Most importantly, we are grateful to the children with progeria and their families, and to the children who participated as control subjects, for their participation in this study. We thank Lorraine Fast for sample collection and processing. We thank several specialists who assisted with helpful discussions: Stacy Croteau (hematologic disorders), Catherine Gordon (pediatric endocrine disorders), and Marie Gerhard-Herman (cardiovascular disease).

\section{STATEMENT OF FINANCIAL SUPPORT}

The Progeria Research Foundation Grants PRF-2002-CB and PRFCLIN200702.

Disclosure: L.B.G. is the parent of a child who participated in the study. The other authors have no conflict of interest to declare.

\section{REFERENCES}

1. Gordon LB, Massaro J, D'Agostino RB Sr., et al. Impact of farnesylation inhibitors on survival in Hutchinson-Gilford progeria syndrome. Circulation 2014;130:27-34.

2. Hennekam RC. Hutchinson-Gilford progeria syndrome: review of the phenotype. Am J Med Genet A 2006;140:2603-4.

3. Gordon LB. PRF By The Numbers: The Progeria Research Foundation; 2013. http://www.progeriaresearch.org/prf-by-the-numbers.html. Accessed 25 September 2013.

4. Gordon LB, McCarten KM, Giobbie-Hurder A, et al. Disease progression in Hutchinson-Gilford progeria syndrome: impact on growth and development. Pediatrics 2007;120:824-33.

5. Merideth MA, Gordon L, Clauss S, et al. Phenotype and Course of Hutchinson-Gilford Progeria Syndrome. N Engl J Med 2008;358:592-604.

6. Domingo DL, Trujillo MI, Council SE, et al. Hutchinson-Gilford progeria syndrome: oral and craniofacial phenotypes. Oral Dis 2009;15:187-95. 


\section{Articles | Gordon et al.}

7. Rork JF, Huang JT, Gordon LB, Kleinman M, Kieran MW, Liang MG. Initial Cutaneous Manifestations of Hutchinson-Gilford Progeria Syndrome. Pediatr Dermatol 2014;31:196-202.

8. Silvera VM, Gordon LB, Orbach DB, Campbell SE, Machan JT, Ullrich NJ. Imaging characteristics of cerebrovascular arteriopathy and stroke in hutchinson-gilford progeria syndrome. Am J Neuroradiol 2013;34: 1091-7.

9. Gordon LB, Kleinman ME, Miller DT, et al. Clinical trial of a farnesyltransferase inhibitor in children with Hutchinson-Gilford progeria syndrome. Proc Natl Acad Sci USA 2012;109:16666-71.

10. Ullrich NJ, Kieran MW, Miller DT, et al. Neurologic features of Hutchinson-Gilford progeria syndrome after lonafarnib treatment. Neurology 2013;81:427-30.

11. Valim C, Ahmad R, Lanaspa M, et al. Responses to bacteria, virus, and malaria distinguish the etiology of pediatric clinical pneumonia. Am J Respir Crit Care Med 2016;193:448-59.

12. Markusse IM, Dirven L, van den Broek M, et al. A multibiomarker disease activity score for rheumatoid arthritis predicts radiographic joint damage in the BeSt study. J Rheumatol 2014;41:2114-9.

13. Gnjatic S, Bronte V, Brunet LR, et al. Identifying baseline immune-related biomarkers to predict clinical outcome of immunotherapy. J Immunother Cancer 2017;5:44.

14. Tehrani DM, Seto AH. Third universal definition of myocardial infarction: update, caveats, differential diagnoses. Cleveland Clin J Med 2013;80:777-86.

15. Statland J, Donlin-Smith CM, Tapscott SJ, van der Maarel SM, Tawil R. Multiplex screen of serum biomarkers in facioscapulohumeral muscular dystrophy. J Neuromusc Dis 2014;1:181-90.

16. O'Neal WK, Anderson W, Basta PV, et al. Comparison of serum, EDTA plasma and P100 plasma for luminex-based biomarker multiplex assays in patients with chronic obstructive pulmonary disease in the SPIROMICS study. J Transl Med 2014;12:9.

17. Nezu T, Hosomi N, Aoki S, et al. Alpha2-macroglobulin as a promising biomarker for cerebral small vessel disease in acute ischemic stroke patients. J Neurol 2013;260:2642-9.

18. Beheiri A, Langer C, During C, Krumpel A, Thedieck S, Nowak-Gottl U. Role of elevated alpha2-macroglobulin revisited: results of a case-control study in children with symptomatic thromboembolism. J Thromb Haemostasis 2007;5:1179-84.

19. Randi AM, Laffan MA. Von Willebrand factor and angiogenesis: basic and applied issues. J Thromb Haemostasis 2017;15:13-20.

20. Lemire JM, Patis C, Gordon LB, Sandy JD, Toole BP, Weiss AS. Aggrecan expression is substantially and abnormally upregulated in HutchinsonGilford Progeria Syndrome dermal fibroblasts. Mech Ageing Dev 2006; 127:660-9.

21. Olive M, Harten I, Mitchell R, et al. Cardiovascular pathology in Hutchinson-Gilford progeria: correlation with the vascular pathology of aging. Arterioscler Thromb Vasc Biol 2010;30:2301-9.

22. McClintock D, Gordon LB, Djabali K. Hutchinson-Gilford progeria mutant lamin A primarily targets human vascular cells as detected by an antiLamin A G608G antibody. Proc Natl Acad Sci USA 2006;103:2154-9.

23. Gordon LB, Harten IA, Patti ME, Lichtenstein AH. Reduced adiponectin and HDL cholesterol without elevated C-reactive protein: clues to the biology of premature atherosclerosis in Hutchinson-Gilford Progeria Syndrome. J Pediatr 2005;146:336-41.

24. Rye KA, Barter PJ, Cochran BJ. Apolipoprotein A-I interactions with insulin secretion and production. Curr Opin Lipidol 2016;27:8-13.

25. Bluher M, Mantzoros CS. From leptin to other adipokines in health and disease: facts and expectations at the beginning of the 21st century. Metabolism 2015;64:131-45.

26. Kaess BM, Preis SR, Lieb W, et al. Circulating brain-derived neurotrophic factor concentrations and the risk of cardiovascular disease in the community. J Am Heart Assoc 2015;4:e001544.

27. Llano DA, Bundela S, Mudar RA, Devanarayan V. Alzheimer's Disease Neuroimaging I. A multivariate predictive modeling approach reveals a novel CSF peptide signature for both Alzheimer's Disease state classification and for predicting future disease progression. PLoS ONE 2017;12:e0182098.

28. Khan W, Aguilar C, Kiddle SJ, et al. A subset of cerebrospinal fluid proteins from a multi-analyte panel associated with brain atrophy, disease classification and prediction in Alzheimer's disease. PLoS ONE 2015;10:e0134368.

29. Chan MK, Krebs MO, Cox D, et al. Development of a blood-based molecular biomarker test for identification of schizophrenia before disease onset. Transl Psychiatry 2015;5:e601. 